\title{
¿Metafísica o Lógica? La significación de Spinoza para la Ciencia de la Lógica de Hegel
}

\section{Metaphysics or Logic? The significance of Spinoza for the Science of Logic of Hegel}

RESUMEN: ¿Debe entenderse la Ciencia de la Lógica de Hegel como un nuevo proyecto metafísico o como un nuevo proyecto de lógica? Dentro de esta discusión abierta, este artículo sostiene la tesis de que la intención de Hegel es post-metafísica. Para apoyar esta tesis, la presunta «refutación» hegeliana de Spinoza en la lógica del ser y la lógica de la esencia es de crucial importancia. Con Jacobi en el trasfondo, este artículo muestra cómo Hegel presenta conscientemente una profunda tergiversación de la metafísica de Spinoza con el objetivo de transformar la ontología de Spinoza en un proceso epistemológico de pensamiento sistemático. Se mencionan finalmente las consecuencias problemáticas de esta transformación en contraste con la convicción de Hegel. PALABRAS ClaVE: Ciencia de la LóGica; Metafísica; Lógica; Post-metafísica; HeGEL; SPINOZA.
ABSTRACT: Is Hegel's Wissenschaft der Logik to be understand as a new project of metaphysics or as a new project of logic? Within this open discussion the article argues for the thesis that Hegel's intention is a post-metaphysical one. In supporting this thesis Hegel's alleged «refutation» of Spinoza in the logic of being and the logic of essence is of crucial importance. With Jacobi in background the article shows how Hegel is consciously presenting a thoroughgoing misinterpretation of Spinoza's metaphysics with the aim of transforming Spinoza's ontology into an epistemological process of systemic thinking. In contrast to Hegel's own conviction the problematic consequences of this transformation are finally mentioned. KEY WORDS: SCIENCE OF Logic; Metaphysics; Logic; Post-Metaphysics; Hegel; Spinoza. 
ÚltimAMENTE SE OBSERVA un nuevo aumento del interés en la Ciencia de la Lógica de Hegel. Esto puede ser debido a la palpitante secuencia de jubileos, pues la Ciencia de la lógica apareció por primera vez entre 1812 y 1816, es decir hace doscientos años. Pero más importante que esta razón externa, pienso que es la visión evidente y aceptada de que la Ciencia de la Lógica de Hegel fundamenta su completo pensamiento, y que por consiguiente, si se quiere alcanzar una adecuada relación con la filosofía de Hegel, ésta ha de ponerse en claro sobre aquel fundamento. Con ello e inmediatamente es convocada la cuestión central: ¿Qué toma forma en la Lógica de Hegel? ¿Es la expresión «Lógica» tan sólo otro nombre para «Metafísica», o es la Ciencia de la Lógica de Hegel una disciplina completamente nueva, que se distancia absolutamente de la metafísica?

Naturalmente, el mismo Hegel favoreció estas cuestiones centrales sobre el sentido y las pretensiones de su obra principal. En el prólogo a la primera edición, y en conexión con la destrucción que de la metafísica había hecho Kant, aclara Hegel que la tarea metafísica es cosa definitivamente pasada ${ }^{1}$. Poco más tarde asevera que la ciencia de la lógica es «la auténtica metafísica» ${ }^{2}$, y por último afirma que la lógica objetiva ocupa «el lugar de la antigua metafísica» ${ }^{3}$. ¿Qué quiere decir Hegel con estas formulaciones? ¿Ha de reemplazar la lógica a la metafísica? $\mathrm{O}$ ¿debe ser la lógica, incluso ocupando el puesto de la antigua metafísica, una nueva metafísica? No cabe duda de que las palabras de Hegel no son claras, y por ello no sorprende que hayan propiciado toda una serie de interpretaciones a favor de la lectura no-metafísica. Según esta interpretación, el alcance exacto de una Ciencia de la lógica, así como el sentido y la finalidad del proyecto hegeliano en conexión con Kant, reside en una continuación de la lógica transcendental.

En realidad, con esto no está aclarada del todo la pregunta. Pues la focalización en Kant, sin duda nos trae pronunciamientos de Hegel en los que él mismo señala el desenlace de la filosofía crítica kantiana. Pero con ello se deja de atender a la circunstancia de que Hegel se refiere a Spinoza en una dimensión por completo pertinente. Sin embargo, esta relación no es tematizada explícitamente ni en los prólogos ni en la introducción. Además, en lugar de manifestar esta relación, él la disimuló en el interior de la Ciencia de la lógica, como si fuese algo ofensivo. Se trata de un fenómeno asombroso, que volveré a tratar más adelante. En cualquier caso este juego del escondite ha provocado que la confrontación de Hegel con Spinoza haya pasado oculta o no haya sido

[1] Georg Wilhelm Friedrich Hegel, Wissenschaft der Logik. Die Lehre vom Sein (1832), según el texto de Hegel en GW 21, nueva edición de Hans-Jürgen Gawoll, Hamburg 2008, 3. En lo que sigue se citará mediante la sigla 'WLS'.

[2] Ibid., 6.

[3] Ibid., 50. 
juzgada como sustancial. Esto ha favorecido su vínculación con Kant. Se trata de faltas graves, porque a un examen más cercano resulta muy claro que para el proyecto hegeliano la relación con la Ética de Spinoza es de una importancia decisiva, casi constitutiva.

¿Qué se sigue de aquí para la pregunta sobre si la Ciencia de la lógica es o no el proyecto de una nueva metafísica? En un primer momento, parece que la respuesta está ya a la mano. Si en esta obra, Hegel no sólo lleva adelante la lógica transcendental kantiana, sino que al menos se considera importante la elaboración de la Ética de Spinoza, entonces se abre el horizonte metafísico. Más aún, en tanto que Hegel no tiene especial interés en la teoría ética de Spinoza propiamente dicha, en particular en su teoría de los afectos, su atención está dirigida casi exclusivamente a la fundamentación metafísica spinozista, que se encuentra en la primera parte de la Ética. Se podría argumentar así. Pero sostengo que esto es falso.

Mi tesis, que quisiera exponer en lo que sigue, es más bien que la empresa de Hegel precisamente en tanto que se la lee en el horizonte de su discusión con Spinoza, se muestra como un proyecto post-metafísico. Con respecto al punto de discusión ya anticipado, para qué exactamente se emplea aquí la expresión «metafísica» y qué quiero decir con la perspectiva de un proyecto "postmetafísico", pienso que sendas preguntas se aclaran y adquieren sentido ante todo en relación con Spinoza. A fin de anticiparme a posibles malentendidos, quisiera hacer una observación previa ya en este momento, desde el comienzo, y es que la tesis arriba enunciada la formulo con intención crítica. Y dice así: no estimo como una ganancia, sino como una pérdida, el que se deba caracterizar el proyecto de lógica hegeliano como proyecto post-metafísico. De aquí se siguen otros dos puntos críticos, que articularan el discurso: no me parece convincente, en primer lugar cómo presenta Hegel la Ética de Spinoza, y con ello se relaciona, en segundo lugar, que su intento de incorporar la posición de Jacobi para sus fines, no puede considerarse acertada.

No he mencionado por casualidad el nombre de Friedrich Heinrich Jacobi. Con Jacobi salta a la escena una tercera figura, junto con las de Kant y Spinoza. Sin duda, Jacobi es tan poco citado en los textos inaugurales de la Lógica como Spinoza, pero esto no supone lo más mínimo acerca de su significado real. Jacobi forma parte esencial del presente contexto, y ha llegado a ser reconocido oficialmente como objeto de [este] debate filosófico, no sólo a causa de la aparición - primero en 1785 y después en una segunda y ampliada edición en 1789-, de su libro Cartas al señor Moses Mendelssohn sobre la doctrina de 
Spinoza. Por todo esto podemos encontrarnos en estas jornadas de congreso sobre «Hegel y Spinoza».

Acerca del hecho de tratar de Jacobi a propósito del llamado «SpinozaRenaissance» hay que destacar tres aspectos de fundamental relevancia que orientan sobre el proyecto de la Ciencia de la lógica ${ }^{4}$. En primer lugar Jacobi formuló un desafío central, al que respondió la Lógica de Hegel, y para el que buscó una solución válida. Este desafío consiste la provocativa alternativa puesta por Jacobi en la forma de una doble filosofía, que él denomina «spinozismo o antispinozismo $»^{5}$ : de una parte cabe elegir la posición de Spinoza y decidirse con ello por el admirable paradigma del monismo, de una metafísica de la inmanencia cerrada en sí misma. Pero por la que se ha de pagar el precio - que Spinoza efectuó consecuentemente-, de abandonar, como un prejuicio insostenible, la libertad de la acción intencional (la causa finalis). La otra parte de la alternativa estriba en elegir, por el contrario, el punto de vista de la libertad personal y renunciar, consecuentemente, a intentar aclararla racionalmente. La filosofía de Spinoza no puede ser refutada a causa de su paradigmática coherencia. Hasta tal extremo llevó Jacobi esta alternativa ${ }^{6}$. Tan sólo cabe contradecirla —-mediante la ejecución de un salto, un «salto mortale» que haga efectiva la convicción de la acción libre como una "certeza inmediata». Es claro que resultaba una tarea urgente (no sólo para Hegel, sino también para Fichte y Schelling) escapar de esta constelación de problemas, y por lo tanto encontrar un camino para refutar el monismo de Spinoza - frente a la afirmación de Jacobi-, y transformar tal monismo en un sistema de la libertad. En la transición de la lógica de la esencia a la del concepto, Hegel acomete expresamente esta tarea de la «refutación del spinozismo» ${ }^{7}$, que desde luego estaba ya en la conocida fórmula programática de la Fenomenología del espíritu, según la cual «hay que comprender y expresar lo verdadero como sujeto y no como sustancia» ${ }^{8}$.

En segundo lugar, es significativo que la reconstrucción de Spinoza por Jacobi haya sido, incluso en el estilo lingüístico, de la mayor influencia y creatividad. En lugar de reproducir la terminología latina de la Ética, Jacobi encontró un nuevo lenguaje para la exposición de la relación de inmanencia y para la

[4] Para una comparación detallada: Birgit SAndkaulen, Grund und Ursache. Die Vernunftkritik Jacobis, München 2000.

[5] Friedrich Heinrich JACOBI, Schriften zum Spinozastreit, in: Werke Gesamtausgabe, hg. v. Klaus Hammacher u. Walter Jaeschke, Hamburg 1998 ss., Band 1,1, 274.

[6] Ibid., 290.

[7] Hegel, Wissenschaft der Logik. Die Lehre vom Begriff(1816), según el texto de Hegel en GW 12, edición de Hans-Jürgen Gawoll, Hamburg 2003, 9 y siguiente. En lo que se sigue se citará como WLB.

[8] Hegel, Phänomenologie des Geistes, nach dem Text Hegel GW 9, nueva edición de HansFriedrich Wessels y Heinrich Clairmont, Hamburg 1988, 14. 
relación entre sustancia y modo, que enunció como «ser en toda existencia» (Sein in allem Dasein) ${ }^{9}$. De nuevo es claro, que Hegel estaba directamente obligado por esta circunstancia. No sólo adopta en diferentes lugares la fórmula «ser en toda existencia», en particular y literalmente al comienzo de la lógica del ser ${ }^{10}$, sino que configuró patentemente con ella la proyección de toda la lógica del ser, que transita por las determinaciones de ser, nada y devenir. Es evidente la razón por la que esto es importante, y que no sólo se trata de una oportunidad extrínseca para el uso de una u otra terminología. Si uno quiere cerciorarse del origen de las determinaciones lógicas fundamentales de Hegel desde el contexto Spinoza-Jacobi, se sigue que la confrontación de Hegel con Spinoza, incluida la provocativa presentación del problema por Jacobi, comienza de hecho en el instante de acceso a la lógica del ser.

Finalmente esto confirma también el que he llamado tercer punto esencial. Tanto lingüísticamente, como fácticamente, la reconstrucción por Jacobi de la Ética destaca porque en lugar de seguir el método de la demostración geométrica, de la secuencia de teoremas y demostraciones, penetra directamente en su centro interior y pone ante los ojos el «espíritu del spinozismo» ${ }^{11}$. Este núcleo esencial y conceptual, desde el que se organiza la Ética de Spinoza, es denominado por Jacobi - justamente al comienzo de su célebre conversación con Lessing- "como el ancestral: a nihilo nihil fit» ${ }^{12}$. De nuevo, Hegel lo incorporó literalmente al comienzo de la lógica del ser y lo adoptó productivamente en la medida en que él extrae patentemente de la proposición de Jacobi las determinaciones de nada y devenir ${ }^{13}$. Más aún: Hegel, no olvidó agradecer a la reconstrucción de Spinoza por Jacobi una nueva proposición, tomada del epistolario sobre Spinoza: «determinatio est negatio». Jacobi la aplica precisamente a la relación de la sustancia con las cosas individuales. Por consiguiente determina las cosas individuales, via negación, como «non-entia» ${ }^{14}$. No resulta,

[9] Jасові, Über die Lehre des Spinoza in Briefen an den Herrn Moses Mendelssohn, según el texto de la edición crticita edictada Marion Lauschke, Hamburg 2000, 45. En lo que sigue será citada como 'Spinozabriefe'.

[10] Hegel, WLS, 107; Hegel, Wissenschaft der Logik. Die Lehre vom Wesen (1813), Según el texto de Hegel en GW 11, nueva edición de Hans-Jürgen Gawoll, Hamburg 1999, 191 (en lo que sigue será citado con las siglas 'WLW'); compárese más adelante la lógica de Hegel en la Enzyklopädie der philosophischen Wissenschaften, en: Theorie-Werkausgabe, hg. v. Eva Moldenhauer u. KarlMarkus Michel, Frankfurt/M. 1969 ff., Band 8, 183. En lo que sigue se citará como 'TWA' con la indicación del tomo y del número de página.

[11] Jасові, Spinozabriefe, 24.

[12] Ibid.

[13] Hegel, WLS, 74. Respecto a este tema, la indicación correspondiente a Jacobi falta extrañamente en el aparato de notas de la «Gesammelten Werke».

[14] Jасові, Spinozabriefe, 95. 
ahora, muy de admirar que Hegel atribuya a esta proposición una «importancia infinita» ${ }^{15}$, e incluso que desde su recensión a Jacobi de 1817, proporcione su peculiar versión: "omnis determinatio est negatio»" ${ }^{16}$. Se puede mantener sin temor a exagerar que nos encontramos aquí con una proposición clave, que Hegel adopta de la fuente de Jacobi. Por una parte él la toma como base decisiva en su confrontación con Spinoza. Y por otra parte se refiere a ella al mismo tiempo nada menos que como el operador fundamental de toda su lógica - en la exacta medida en que la desarrolla hacia la operación de la «negación de la negación»-.

En resumen, esta concisa vista panorámica arroja como resultado, lo que, por desgracia, en la investigación sobre Hegel no siempre está suficientemente presente, y que ha de ser tenido en cuenta: que la confrontación de Hegel con Spinoza no se puede debatir razonablemente sin tener en cuenta el envite de Jacobi. Este contexto compromete decisivamente tanto al completo programa de la lógica - la refutación de Spinoza en el sentido de la transformación de la sustancia en sujeto- como a las determinaciones lógicas fundamentales (ser, nada, devenir, existir) y por último y no menos importante al operador central de la negación, que Hegel pone desde el principio para la realización de su programa lógico.

Si ante este complejo de temas y problemas aún permaneciera alguna duda, se disiparía definitivamente, se derrumbaría con facilidad: Hegel situó abiertamente y con toda la claridad deseable, las coordenadas esenciales de su proyecto lógico en la ya mencionada recensión a Jacobi. Este texto, que tengo por uno de los más importantes de Hegel, es particularmente revelador. Lo escribió en Heidelberg en 1817 facilitando información programática acerca de su pretensión. Un año antes había concluido la Ciencia de la lógica, y esto implica que Hegel recapituló en la recensión a Jacobi su proceder.

Jacobi, así lo dice Hegel en este texto, ha mostrado frente «a la ingenuidad de la degenerada metafísica leibniziano-wolffiana» «que todo filosofar consecuente ha de conducir al spinozismo ${ }^{17}$. Este es el punto de partida, que Hegel determina como «lo verdadero en esta su primera inmediatez»" ${ }^{18}$. Igualmente es completamente correcto, prosigue Hegel, que Jacobi también reconoció que uno no puede quedarse en Spinoza. Porque «el ser infinito en esta inmediatez es solo lo abstracto, inmóvil, no espiritual; lo libre, como lo que se determina a sí desde sí mismo, se pierde en aquel abismo, en el que se echan y se hacen añicos todas las determinaciones; la libertad es para sí inmediatamente perso-

[15] HegeL, WLS, 107.

[16] Hegel, Friedrich Heinrich Jacobis Werke, in: TWA 4, 434.

[17] Ibid., 432.

[18] Ibid., 433. 
nalidad, en tanto que el punto infinito del determinar-en-y-para-sí.» ${ }^{19}$ La meta de la empresa es por ello defender esta libertad frente a Spinoza.

Sin embargo, Hegel observa críticamente que Jacobi eligió un camino equivocado para alcanzar este objetivo. Hegel opone a la certeza inmediata de la libertad, un proceso lógico. Por medio de este proceso se parte de Spinoza para alcanzar la inmediatez mediada de la libertad. Éste no es sino el proceso de la negación de la negación, que Hegel relaciona con la apropiación de la proposición trasmitida por Jacobi, y de la que aquí y por primera vez proporciona la versión: «omnis determinatio est negatio». La «absoluta negatividad» dice Hegel es «la fuente de la libertad ${ }^{20}$ y explica cómo entender este pensamiento: «Pero como, por el contrario, la negación es en la sustancia, como ya hemos dicho, y la progresión sistemática en el trabajo filosófico no consiste propiamente más que en saber lo que uno mismo ya ha dicho, la sustancia debe ser, en efecto, el sersuperado de lo finito. Con ello uno afirma que ella es la negación de la negación, puesto que a lo finito se le da solo como la negación; en tanto que negación de la negación la sustancia es la afirmación absoluta y también inmediatamente libertad y autodeterminación.» ${ }^{21}$

No cabe duda alguna acerca del punto de partida ni de la meta, ni tampoco acerca del método de la Ciencia de la lógica. También es claro que Hegel transita, según sus palabras, el camino del "progresar sistemático en el filosofar» para superar tanto la posición de Spinoza como la doble filosofía de Jacobi: es inequívoco que el "progresar sistemático» ha de reemplazar al salto, al «salto mortale». Cosa muy distinta es enterarse del proyecto de Hegel de este modo, o incluso preguntar si este proyecto es plausible. Ahora vuelvo al texto de la Ciencia de la lógica para discutir prolijamente los problemas que advierto aquí.

Recuerdo haber insinuado que el completo programa de la lógica de Hegel, que he presentado esquemáticamente, se encuentra en cierta medida oculto en el texto de la Ciencia de la lógica. Entretanto se ha clarificado el motivo de esto: de hecho se debe distinguir entre los textos hegelianos exotéricos, en los que él habla acerca de sus intereses (a los cuales pertenece la exposición de Spinoza en las Lecciones sobre la Historia de la Filosofía), y el texto de la Lógica, en el que desarrolla esos intereses implícitamente. En el último caso, la filosofía de Spinoza representa algo así como un presupuesto no tematizado de la totalidad de la lógica, que ya en el comienzo ha sido aceptado y que tan sólo

[19] Ibid. 433. Traducción de Gabriel Amengual en Escritos sobre Religión, Sígueme, Salamanca, 2013. p., 60.

[20] Ibid., 434.

[21] Ibid., 434 f. Trad. de Gabriel Amengual, cit., pp. 61-62. 
en el interior del progreso lógico puede llevarse a lenguaje y así ser superado. Es del todo consecuente que Hegel hable por primera vez explícitamente del programa de «refutación del spinozismo» en el tránsito de la lógica de la esencia a la lógica del concepto.

No obstante con esta declaración explícita está vinculada una grave dificultad. Si se observa atentamente, entonces parece que Hegel localiza retrospectivamente la llamada refutación de Spinoza en un punto muy específico de la lógica de la esencia: el capítulo sobre la «relacion absoluta» que conduce de la relación de sustancialidad al concepto como determinación de la subjetividad libre a través de la relación de causalidad y la acción recíproca. Aunque Hegel no menciona en el lugar citado a Spinoza por su nombre, no obstante se sigue de esta constelación [de temas] que Hegel identifica aquí la relación de sustancialidad con la filosofía de Spinoza. ¿Dónde está el problema? La dificultad reside en que esta referencia a Spinoza no se ajusta con la discusión de Spinoza que Hegel había acometido en lugares anteriores de la lógica de la esencia, en los que trataba de «lo Absoluto». En lugar de hablar de una relación de la sustancia, Hegel establece aquí el "concepto de la sustancia spinozista», en la deficitaria determinación de una «identidad abstracta» ${ }^{22}$.

Por lo tanto, en lugar de tener que habérnoslas con una exposición de Spinoza en la lógica nos encontramos con dos versiones diferentes y no compatibles entre sí de Spinoza ${ }^{23}$. Esto significa que Hegel usa abiertamente una doble estrategia para tratar el desafío de Spinoza (y la doble filosofía de Jacobi). En lo que sigue, prestaré atención a esta doble estrategia altamente problemática, y partiré del comienzo de la lógica del ser. Ahí nos encontramos con un fenómeno chocante. Hegel en la segunda edición corregida de la Ciencia de la lógica de 1832 desarrolló significativamente lo relativo a Spinoza en la lógica del ser. Y eso aún cuando por lo ya dicho tan sólo se lo encuentre en las así llamadas observaciones ${ }^{24}$. Pienso que esta modificación responde a una decisión estratégica ${ }^{25}$, con la que Hegel, al fin y al cabo subraya más claramente que en la primera edición de la Lógica que la confrontación con Spinoza comienza realmente en la lógica del ser. ¿Cuáles son los rasgos esenciales de esta discusión?

[22] Hegel, WLW, 167.

[23] He discutido en detalle estos resultados en: cfr.: Birgit SANDKAulen, „Die Ontologie der Substanz, der Begriff der Subjektivität und die Faktizität des Einzelnen. Hegels reflexionslogische ,Widerlegung' der Spinozanischen Metaphysik«, en: Internationales Jahrbuch des Deutschen Idealismus/International Yearbook of German Idealism 5 (2007), Berlin, New York 2008, 235-275.

[24] Las mismas consideraciones son válidas para lo referente a Jacobi.

[25] En mi ya mencionado ensayo, he argumentado que Hegel adelanta el capítulo de la lógica de la esencia sobre el Absoluto. En la lógica enciclopédica falta el capítulo sobre el Absoluto. 
La primera mención a Spinoza es ya significativa y al mismo tiempo bastante problemática. Según Hegel cabe atribuir verdaderamente tanto a Parménides como a Spinoza ${ }^{26}$, la inicial determinación de la lógica, el «simple pensamiento del puro ser». Según Hegel, la base de ambos casos es el parecer de que «ser es sólo ser, nada sólo nada». De la misma manera es tratada la «identidad abstracta» como "esencia del panteismo»" ${ }^{27}$. Este paralelismo entre eleatismo y spinozismo es realizado de nuevo en las Lecciones de Historia de la Filosofía, donde se dice que la «intuición oriental» fue «enunciada por vez primera en Occidente por Spinoza $»^{28}$.

Esta declaración es visiblemente ambivalente. De una parte, subraya que tanto Parménides como Spinoza alcanzaron el pensamiento del ser, que en su pura indeterminación no puede ser sino abstracto. De otra parte, y como Hegel un poco más adelante hará notar expresamente, muestra el déficit decisivo de estas filosofías: «Ni en Parménides ni en Spinoza cabe transitar del ser o de la sustancia absoluta a lo negativo, a lo finito. ${ }^{29}$ Con otras palabras: lo que queda establecido desde el comienzo en el curso de este paralelismo es el teorema del llamado "acosmismo» ${ }^{30}$. Frente a esta tesis, Hegel considera como su propio interés en el discurrir de la lógica, hacer valer el mundo en toda su concreción, mediante la aplicación de la negación.

La rotunda aseveración de acosmismo, que asegura a Spinoza su posición inicial en la Lógica, garantiza simultáneamente desde el comienzo que el proceso lógico ha de transitar sobre el déficit de tal abstracción, y fundamenta la larga respuesta que Hegel da a Spinoza en la observación a Dasein. "Aquel real en todo lo real, el ser en toda existencia, que debe expresar el concepto de Dios, (en lo que, como hemos visto, cita las Cartas sobre Spinoza de Jacobi) no es otro que el ser abstracto, es lo mismo que la nada.» ${ }^{31}$ Comoquiera que esto no es sino una repetición del estado de cosas ya mencionado, añade Hegel a continuación «la infinita importancia» de la proposición «Omnis determinatio est negatio». No obstante, para Spinoza, explica Hegel, «la negación como tal es la abstracción carente de forma» ${ }^{32}$.

[26] HegeL, WLS, $73 \mathrm{f}$.

[27] Hegel, Vorlesungen über die Geschichte der Philosophie, in: TWA 20, 165.

[28] Hegel, Vorlesungen über die Geschichte der Philosophie, in: TWA 20, 165.

[29] Hegel, WLS, 87.

[30] En la Ciencia de la lógica no aparece literalmente la palabra clave «acosmismo», pero Hegel la usa en muchos otros lugares como su famosa descripción de la filosofía spinozista: así en las Vorlesungen zur Geschichte der Philosophie (TWA 20, 177) y en la Enzyklopädie der philosophischen Wissenschaften (TWA 8, $\$ 50$ (133 f.); TWA 10, $\$ 573$ (387)).

[31] Hegel, WLS, 107.

[32] Ibid., $107 \mathrm{f}$. 
Y precisamente ahí es desde donde debe explicarse el hecho de que y el modo como de la mencionada frase resulta «la unidad de eso que Spinoza llama substancia», es decir, que cualquier diferencia, también la diferencia de los atributos y de los modos, no sólo no tiene ningún significado ontológico, sino que estas diferencias no pueden ser caracterizadas como «momentos» de la sustancia, porque tan sólo cabe encontrarlas mediante un «entendimiento externo $»^{33}$. A la vista del individuo finito se enuncia el resultado correspondiente de «que lo finito como tal esté en sí y por sí, se hace valer la determinación esencialmente como negación que arrastra lo finito en el mismo movimiento negativo del intelecto, movimiento que hace desaparecer todo en la unidad abstracta que es la sustancia» ${ }^{34}$. La ontología de Spinoza, - ésta es la conclusión de Hegel, que se corresponde con la versión sobre el Absoluto en el capítulo de la lógica de la esencia ${ }^{35}$-, termina bajo el signo del ser abstracto y el aniquilamiento de lo finito.

¿Qué se debe pensar de esta presentación de Hegel? Lo único que se puede traer a colación a favor de Hegel, es la ya mencionada circunstancia de que él desbarata esta versión mediante otra - la relación de sustancialidad-, lo que, sin embargo, no mejora mucho la cosa. Antes de inclinarme por esta versión, mantengo con firmeza en este momento, que la interpretación acosmística de Spinoza, incluyendo el paralelismo entre Spinoza y Parménides, está desorientado por completo. Pues de que las cosas finitas, sean para Spinoza modos de la sustancia y no de por sí sustancias, no se sigue evidentemente que no tengan ningún significado ontológico. Tanto en lo que respecta a su esencia como en lo que respecta a su existencia temporal tienen una caracterización ontológica diferente de la de la sustancia. En ellas se expresa más bien la esencial potencia productiva de la misma sustancia, y esto no las aproxima a la sustancia tan sólo aparentemente, como para un «entendimiento extrínseco».

La exposición hegeliana de Spinoza es — a primera vista - tan por completo equivocada, que resulta sorprendente que pueda apelar en modo alguno a Jacobi. Parece, por la recensión a Jacobi, que Hegel podía apropiarse de las ideas de Jacobi, pero en realidad no hay ninguna duda. La diferencia fundamental entre las exposiciones de Hegel y de Jacobi es fácil de advertir en la conversación

[33] Ibid., 108.

[34] Ibid.

[35] Con la excepción del rechazo pormenorizado del método geométrico, que Hegel efectúa en el capítulo de la lógica de la esencia sobre el Absoluto, y que sin embargo falta en la lógica del ser corregida: aparentemente porque la lógica del ser aún no tematiza propiamente la reflexión como sí lo hace la lógica de la esencia, y de modo correspondiente tampoco puede ocuparse de los diferentes procedimientos metódicos. Esto muestra cuáles son las dificultades que Hegel tiene para ubicar estratégicamente la confrontación con Spinoza. Confróntese aquí mi ya mencionado artículo. 
de Jacobi con Lessing. Quedando determinado en ellas el «espíritu del spinozismo» desde el «a nihilo nihil fit», lo que se sigue inmediatamente no es como en Hegel el acosmismo de un ser abstracto. Más bien lo que de ahí se sigue es que Spinoza rechazó «cualquier tránsito de lo infinito a lo finito» poniendo «en lugar del Ein-Sof ${ }^{36}$ emanente, un Ein-Sof meramente inmanente», «una causa del mundo que habita interiormente, y que en sí misma es eternamente inmodificable, la cual, tomándola junto con todas sus secuencias, sería con ellas una misma y única cosa». ${ }^{37}$

Es claro de qué depende esto: El objetivo de Jacobi está en el centro de la ética, y por lo tanto en la metafísica spinozista de la inmanencia, cuya determinación esencial es la causa immanens. Con otras palabras, esto implica que se ha de entender lo que es la sustancia y lo que de ella se sigue, como una relación inseparable y simultánea. No hay ningún tránsito entre los dos. Esto significa que no tiene ningún sentido aislar la sustancia - como un principio exclusivo- de lo que se sigue de ella. Más aún, el punto culminante de la filosofía de Spinoza, reside por el contrario en la tesis de que Dios es, en el mismo sentido, causa sui y omnium rerum causa ${ }^{38}$. Y exactamente así comprende Jacobi este pasaje ${ }^{39}$. Por último es también claro, que con su anteriormente mencionada determinación de las cosas finitas como «non-entia», en ningún caso quería significar su nada ontológica. Más bien, con el uso de la negación sólo quería llamar la atención sobre la relación de dependencia entre «Sein» y «Dasein», entre sustancia y modos.

Todo esto podía haberlo examinado Hegel, y de hecho atendió, como he mostrado, a la fuente de Jacobi. Pero lo que él descubrió en esta fuente, recibió frente a la versión original de Jacobi un sentido completamente diferente, que no sólo falsifica las afirmaciones de Jacobi y Spinoza ${ }^{40}$, sino que construye con la Ética de Spinoza una teoría completamente nueva y no spinozista. ¿Por qué procede Hegel así? Parte de la respuesta es que la realización de su Ciencia de la Lógica debe acercarse al mérito de avanzar de lo abstracto a lo concreto, que supuestamente no se da en Spinoza. No obstante es más importante conside-

[36] Nota del traductor: Ein-Sof es un término cabalístico que nombra a Dios antes de que se manifieste a sí mismo.

[37] JАсові, Spinozabriefe, 24.

[38] Baruch de Spinoza, Ethica, I, prop. 25, scholium.

[39] JАСові, Spinozabriefe, 106.

[40] Esto incluye también, dicho sea de paso, la presentación basal tanto del mismo Spinoza como la reconstrucción de Spinoza por Jacobi bajo la palabra clave de la inmediatez. Acerca de este campo de problemas del así llamado saber inmediato véase mi artículo: Birgit SANDKAULEN, „Dritte Stellung des Gedankens zur Objektivität: Das unmittelbare Wissen «, en: Alfred DenkeR, Annette Sell y Holger Zaborowski (Hg.), G.W.F. Hegel, Der „Vorbegriff "zur Wissenschaft der Logik in der Enzyklopädie von 1830, Freiburg 2010, 166-191. 
rar que el establecimiento hegeliano de la Ética sobre el ser abstracto carente de determinación, obedece obviamente a una medida estratégica: tan sólo si se fija la metafísica de Spinoza — en contra de su sentido genuino- sobre la «identidad abstracta», puede Hegel integrarla en la Lógica, como su comienzo, de modo que se pueda superar este comienzo en el proceso ulterior. Este punto tiene un alcance considerable, por lo que quisiera subrayarlo expresamente y reformularlo una vez más:

De una parte, carece obviamente de sentido, reducir la filosofía de Spinoza a la sustancia y al mismo tiempo suponer que «del ser o de la sustancia absoluta no hay tránsito a lo negativo, lo finito». No tiene sentido porque el concepto spinozista de causa immanens excluye precisamente tal «tránsito», y la sustancia se expresa «ya siempre» en sus atributos y modos. Jacobi llamó a esta relación «ser en todo ser». En este sentido es tan sólo obra de Hegel el destruir la relación de inmanencia y poner en su lugar el ser abstracto. Por otra parte, se ha de ver qué implica este proceder y por qué motivo no resulta extraño a una segunda inspección, por qué y hasta qué punto Hegel dispone la filosofía de Spinoza para sus propios fines. Pues mientras que Hegel afirma contra el genuino sentido de la ontología spinozista, que no se da ningún tránsito del ser a la existencia, produce la impresión de una argumentación ontológica. En realidad no se da tal cosa, sino más bien un interés epistémico. De lo que aquí se trata es del interés del pensar, que en la lógica de la esencia sale a la luz como interés de la reflexión, como el organizar un "progresar sistemático del filosofar»: en la forma de un desarrollo sucesivo de determinaciones del pensamiento, que conducen finalmente al concepto como Idea de un concebir devenido completamente transparente para sí.

Que Hegel llame a este interés del pensar un «pensar objetivo» remite a su distanciamiento de Kant. De aquí se sigue que la Ciencia de la lógica en tanto que aclara como su contenido «el pensamiento en tanto que es la cosa en sí misma, o la cosa en sí en tanto que es el puro pensamiento»" ${ }^{41}$, sigue por completo una orientación ontológica. No obstante, se deduce claramente de la relación de Hegel con Spinoza, dónde y cómo se ha de poner el acento en esto: el diseño de una onto-lógica científica, en la que el pensar - y no el ser- ha de hacerse cargo de la dirección. La tesis que formulé inicialmente toma forma: Hegel escribe una nueva metafísica. Lo que él escribe es precisamente aquello de que informa el título de su obra principal: una Ciencia de la lógica.

Si se comprende este diagnóstico - a saber, un diagnóstico arrojado por la peculiar e insólita integración hegeliana de la filosofía spinozista en su lógi$\mathrm{ca}-$, entonces se perfila en este momento que el Absoluto que Hegel alcanza al final de la Lógica no puede ser comprendido de ningún modo como una

[41] Hegel, WLS, 33.

Studia Hegeliana vol. I (2015) 
figura ontológica alternativa a la sustancia, cuya supuesta rigidez e inmovilidad abstractas es transformada en la forma de una dinámica viva. Resulta decisivo en Hegel este cambio radical de signo bajo el título de lógica. El Absoluto es resultado, y lo es precisamente en la medida en que es resultado de un movimiento epistémico, y no ontológico. Hegel denomina a esto «sujeto» como expresión terminal, teniendo en cuenta que el desarrollo del pensar ha llegado a la completa conciencia de sí mismo - a la autoconciencia- ${ }^{42}$

Finalmente voy a examinar las consecuencias aludidas que resultan del radical cambio de signo hegeliano. En primer lugar examinaré lo que concierne a la confrontación con Spinoza. Como se ha indicado desde el comienzo, se confirma en el transcurso ulterior de la lógica, que la exposición de Hegel no tiene sencillamente nada que ver con la Ética de Spinoza. Es una grave omisión de muchas interpretaciones de Hegel, no prestar atención al debate de Hegel con Spinoza y al transfondo jacobiniano de esta problemática. Y a la inversa, no pueden tampoco ser atinadas las declaraciones de Hegel sobre Spinoza como objeciones sólidas frente a la Ética o considerarlas como asunto de una discusión juiciosa. Ni siquiera la suposición de un margen hermenéutico para una comprensión o un malentendido que puedan resultar productivos afecta al asunto, por los motivos que ya hemos mencionado, pues el interés de Hegel no es Spinoza, sino la integración de Spinoza en el devenir epistémico de la lógica.

Con la relación de sustancialidad, Hegel introduce una segunda versión de Spinoza, que respecto a la primera que acabamos de discutir, se diferencia precisamente en que tematiza no la identidad abstracta de la sustancia, sino ante todo la relación inmanente de la sustancia para con sus accidentes, y documenta esto directamente y con toda la claridad deseable. En claro contraste con la primera versión, - que Hegel sostenía que no era más que un «entendimiento extrínseco», en el que la distinción de los atributos y las cosas finitas acercaban a la sustancia, a la que igualmente desbarataban-, la segunda versión trata sobre el «poder absoluto» y la «actuosidad» (Aktuosität) de la sustancia ${ }^{43}$. Con ello Hegel se orienta, al fin y al cabo, claramente hacia las declaraciones reales de la Ética. Por este motivo, tampoco es recomendable tomarse en serio el veredicto de acosmismo.

No obstante y en el caso de la segunda versión, aunque parece más cercana a la Ética, no tiene absolutamente nada que ver con una exposición

[42] Consecuentemente, y desde una perspectiva lógica, es preciso tratar con gran cautela las diferentes expresiones hegelianas acerca de «Dios», pues bajo este nombre no se puede tratar expresamente ya de la usual representación de Dios.

[43] Hegel, WLW, 192 f. 
convincente de Spinoza. Esta es impedida por el hecho de que Hegel distingue la relación causal de la sustancial, y que como siguiente paso en el despliegue de las determinaciones del pensar, aparece que la «actuosidad absoluta» de la sustancia es la «causa» y su poder se manifiesta en el «efecto» ${ }^{44}$. Es claro que según Spinoza - es decir desde un punto de vista ontológico- no se pueden separar estas determinaciones, y que la distinción entre poder y causa no tiene aquí ningún sentido. ¿Qué permiso tiene Hegel para suponerlo? Él sabe bien lo que le importa en esto, como se evidencia reiteradamente: su interés lógico muestra separada y sistemáticamente lo que para Spinoza es simultáneo, porque epistémicamente se trata del desarrollo sucesivo y del enriquecimiento de las determinaciones pensables. En una palabra del "progresar sistemático en el filosofar».

Hegel presenta los temas particulares de la secuencia mostrada en el tránsito a la lógica del concepto como la «única y verdadera refutación del spinozismo» y afirma esta presunta refutación como el «desvelamiento de la sustancia». ${ }^{45}$ Consiguientemente la epistémica "génesis del concepto» ${ }^{46}$ presupone de hecho la sustancia. Esto confirma de nuevo, en un lugar decisivo, tanto el significado constitutivo de Spinoza para el proyecto hegeliano, como la disposición lógica de Spinoza en este proyecto. La ontología de la Ética es transformada literalmente en una Ciencia de la lógica. Se puede dejar confiadamente en suspenso si Hegel mismo cree, como dice de su proceder, que «la verdadera refutación» ha de "penetrar en la fuerza del adversario y colocarse en el ámbito de su vigor ${ }^{47}$, o si se trata tan sólo de una asegurarse estratégicamente un lugar en la discusión con sus contemporáneos. Por ahora es suficientemente claro que Hegel atiende a la fuerza del proyecto spinozista sólo para inscribirlo desde el comienzo en un movimiento pensante, que no «revela» la filosofía de Spinoza, sino que se distancia sistemáticamente de ella en su interés fundamental.

Concluyo con esta observación, pues querría indicar las graves consecuencias de esta distanciamiento. No basta, afirmar sin más como resultado de la discusión que en las filosofías de Spinoza y de Hegel tratamos manifiestamente con diferentes conceptos filosóficos toto genere, acerca de los cuales no se puede hablar en absoluto de modo comparativo, ni movernos entre los mismos en el mismo plano o en el mismo horizonte. Aunque esta afirmación es verdadera, no basta con ella, pues la conocida «refutación del spinozismo» hegeliana está

[44] Ibid., $195 \mathrm{f}$.

[45] Hegel, WLB, 10.

[46] Ibid.

[47] Ibid. 
conectada con costes notables en lo que respecta al contenido. Costes sobre los que es preciso reflexionar acerca de si se quiere pagar tal precio. Al comienzo de esta conferencia identifiqué este alto precio como el pensamiento postmetafísico de Hegel. He puesto de relieve su condición operativa, es decir, la transformación de la ontología en el «progresar sistemático» en una onto-logica orientada epistémicamente.

¿Cuáles son las consecuencias respecto al contenido? De nuevo tenemos que es en el tránsito de la lógica de la esencia a la del concepto, donde estas consecuencias salen a la luz del modo más claro. En la esbozada secuencia de la relación de sustancialidad a través de la de causalidad y de acción recíproca al concepto, no sólo traza Hegel un desarrollo epistémico separado del de Spinoza. Se trata más bien de que con esta denominada por Hegel «revelación de la sustancia», de hecho se desconstruye la diferencia presente en la relación de sustancialidad entre la sustancia y las cosas finitas, y se la metamorfosea en una «identidad que está siendo en y para sí» ${ }^{48}$ como la relación consigo del sujeto. Para Hegel, con esta estructura se supera cualquier distinción ontológica entre lo infinito y lo finito, y entre los individuos finitos entre sí, y se alcanza lo que enfáticamente denomina «libertad ${ }^{49}$.

Pero en lo referente a la lógica, esta liberación estaba encarrilada desde hacía tiempo. Con el uso del operador lógico de la negación de la negación era ya usada en la lógica del ser, donde en conexión con las determinaciones de existencia y finitud, se alcanzó el punto de vista decisivo en el «verdadero infinito», en el que la oposición entre lo finito y lo infinito ha desaparecido. ${ }^{50}$ No es ninguna casualidad que Hegel dedique tantos esfuerzos al desarrollo de esta determinación, pues aquí reside abiertamente el enunciado principal de su propio planteamiento, que explicitará sucesivamente y que expresará completamente en el concepto. A primera vista parece que este holismo de Hegel es una variación del de Spinoza. Pero sólo lo parece. Hegel, en el curso de su doble estrategia reprocha a Spinoza, de una parte su carencia de diferencia, y de otra la carencia de una verdadera identidad. Así disuelve fundamentalmente la estructura ontológica de la Ética para sustituirla por la completa transparencia de una relación consigo en el saber.

Mis reservas frente a este proceso lógico de la liberación no obedecen a la objeción estereotipada de que no existe tal cosa como un «saber absoluto». Al fin y al cabo, Hegel muestra en la Ciencia de la Lógica de qué tipo de saber se trata aquí y en qué medida es muy posible alcanzar la transparencia a la que se aspira en el proceso de una sucesiva aclaración exhaustiva de las de-

[48] Ibid., 11.

[49] Ibid.

[50] HegeL, WLS, 135. 
terminaciones del pensamiento. Más bien, mis reservas se basan exactamente en el hecho de que, tal como vio claramente Hegel, depende de la condición decisiva de transformar la ontología en una onto-lógica. Frente a ello, sostengo el convencimiento fundamental de que la facticidad de la realidad no se puede aprehender por completo con el pensamiento, y de que la experiencia óntica de la finitud propia se enfrenta permanentemente al pensamiento - aducido como siempre concluyentemente- de una identidad de lo infinito y lo finito. En tal medida, mi alegato de defensa - con el que concluyo esta conferenciano se refiere al pensamiento postmetafísico de Hegel, sino a la opción de que aquello entre lo que hay que decidir siguen siendo las posiciones respectivas del spinozismo y del antispinozismo. 